\title{
Rare association of juvenile retinoschisis with retinochoroidal coloboma
}

\author{
Deepika C Parameswarappa, Komal Agarwal
}

Srimati Kannuri Santhamma Center for Vitreo-retinal Diseases, LV Prasad Eye Institute, Hyderabad, Telangana, India

\section{Correspondence to} Dr Komal Agarwal, komal.agarwal.vr@gmail.com

Accepted 12 July 2019

\section{DESCRIPTION}

A 20-year-old man presented with history of diminution of vision since 8 years. On examination his best corrected visual acuity was 20/20 in the right eye and 20/200 in the left eye. Anterior segment examination was essentially normal in both eyes. Right eye fundus showed stellate maculopathy with schitic changes in the foveal region (figure 1A). Left eye fundus showed stellate maculopathy with schitic changes in the foveal region and an isolated wedge-shaped retinochoroidal coloboma in the inferior fundus (figure 1B). The retinochoroidal coloboma in the left eye was not involving the disc or macula. Optical coherence tomography of both eyes showed altered foveal contour, increased central macular thickness and schitic changes in the inner retinal layers with splitting of the retinal layers at the level of outer plexiform and

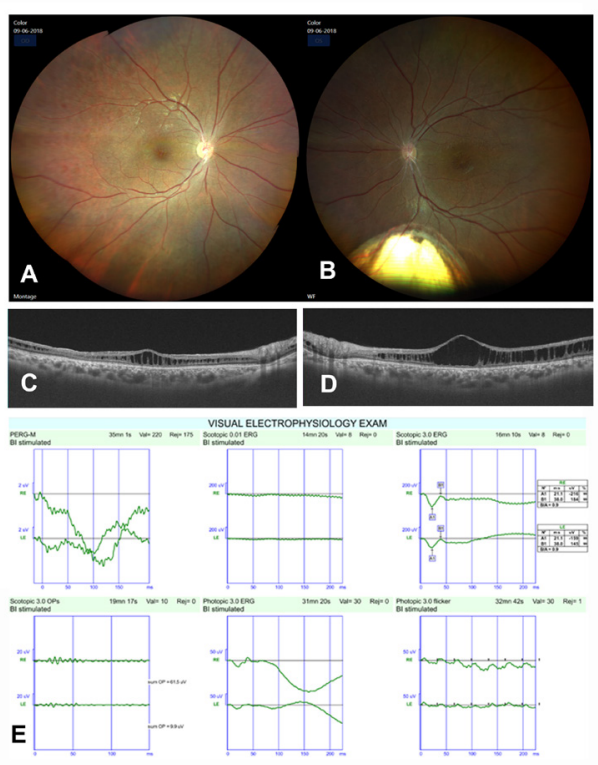

Figure 1 (A) Right eye fundus showed stellate maculopathy with schitic changes in the foveal region. (B) Left eye fundus showed stellate maculopathy with schitic changes in the foveal region and an isolated wedge-shaped retinochoroidal coloboma in the inferior fundus. (C) (Right eye) and (D) (left eye) optical coherence tomography of showed altered foveal contour, increased central macular thickness and schitic changes in the inner retinal layers with splitting of the retinal layers at the level of outer plexiform and inner nuclear layer. (E) Electroretinogram of both eyes showed reduced photopic and scotopic responses with reduced oscillatory potential. inner nuclear layer (figure 1C, D). Electroretinogram of both eyes showed reduced photopic and scotopic responses. Both eyes showed reduced oscillatory potential (figure 1E). A diagnosis of juvenile retinoschisis was made based on fundus features and ancillary tests. The patient and family members were counselled regarding the disease nature, prognosis and genetic association. Topical dorzolamide BD was prescribed for the macular schitic changes.

Congenital retinoschisis is a rare bilateral condition characterised by vitreous degeneration and splitting of the retina between the nerve fibre and ganglion cell layers. Patients will typically have a cystic-like stellate maculopathy or a foveal schisis with or without peripheral retinoscisis. ${ }^{1}{ }^{2}$ It is an X-linked recessive trait with mutation in RS 1 (XLRS1) gene, occurring mostly in males. ${ }^{2}$ Optical coherence tomography and electroretinogram aids in confirmation of diagnosis. In our case, the macular schisis and electroretinogram findings were in favour of the juvenile retinoschisis. Reduction of a wave amplitudes in our case can be explained by affection of both photoreceptors and inner retinal layers. ${ }^{3}$ There have been few reports wherein acquired retinoschisis and retinochoroidal coloboma have been described in the same patient. Juvenile retinoschisis with concurrent presence of morning glory coloboma has been described in one report so far. ${ }^{4}$ The concurrent presence of retinoschisis and coloboma in our case can be explained in terms of mutations in the XLRS1 gene, which may affect embryonic differentiation that can also lead to colobomatous change as described in earlier case report. ${ }^{4}$ However, in our case the genetic evaluation was not conducted as the patient and family members did not give consent for genetic testing. The presence of peripheral coloboma in our case can be due to same genetic origin of both disease and it can also be linked with the embryonic evolution of the eye as the coloboma in our case is inferior and peripheral in line with the closure of embryonic fissure.

\section{Patient's perspective}

Medical counselling helped me and my family members to have better understanding of the disease nature, its inheritance pattern and prognosis. 


\section{Learning points}

- Association of juvenile retinoschisis with coloboma or any other embryonic defects should be kept in mind owing to common differentiation of structures embryonically due to mutations in XLRS1 gene.

- Counselling of patients and the family members in any rare disorder regarding nature of disease is an important part of clinical practice for improvement of quality of clinical care.

- Regular follow up should be advised to the patient and parents and the patient should be monitored for progression.

Contributors KA was involved in conception and design, acquisition of data, analysis and interpretation of data, and final approval of the version published. DCP was involved in drafting the article or revising it critically for important intellectual content. Both the authors are accountable for the article and to ensure that all questions regarding the accuracy or integrity of the article are investigated and resolved.

Funding The authors have not declared a specific grant for this research from any funding agency in the public, commercial or not-for-profit sectors.

Competing interests None declared.

Patient consent for publication Obtained.

Provenance and peer review Not commissioned; externally peer reviewed.

\section{REFERENCES}

1 Deutman AF. Sex-linked juvenile retinoschisis. The hereditary dystrophies of the posterior pole of the eve, 1971:48-98.

2 Miyake Y, Shiroyama N, Ota I, et al. Focal macular electroretinogram in X-linked congenital retinoschisis. Invest Ophthalmol Vis Sci 1993;34:512-5.

3 Bradshaw K, George N, Moore A, et al. Mutations of the XLRS1 gene cause abnormalities of photoreceptor as well as inner retinal responses of the ERG. Doc Ophthalmol 1999;98:153-73.

4 Gonzales JA, Tawansy KA, Simon A, et al. Chorioretinal Coloboma in Juvenile X-linked Retinoschisis. Invest Ophthalmol Vis Sci 2005;46:546.

Copyright 2019 BMJ Publishing Group. All rights reserved. For permission to reuse any of this content visit

https://www.bmj.com/company/products-services/rights-and-licensing/permissions/

BMJ Case Report Fellows may re-use this article for personal use and teaching without any further permission.

Become a Fellow of BMJ Case Reports today and you can:

- Submit as many cases as you like

- Enjoy fast sympathetic peer review and rapid publication of accepted articles

- Access all the published articles

- Re-use any of the published material for personal use and teaching without further permission

\section{Customer Service}

If you have any further queries about your subscription, please contact our customer services team on +44 (0) 2071111105 or via email at support@bmj.com.

Visit casereports.bmj.com for more articles like this and to become a Fellow 